\title{
Texture, Color, and Sensory Features of Low-Sugar Gooseberry Jams Enriched with Plant Ingredients with Prohealth Properties
}

\author{
Anna Banaś, ${ }^{1,2}$ Anna Korus $\left(\mathbb{D},{ }^{1}\right.$ and Jarosław Korus ${ }^{3}$ \\ ${ }^{1}$ Department of Fruit, Vegetable and Mushroom Processing, Faculty of Food Technology, \\ University of Agriculture in Krakow, Krakow, Poland \\ ${ }^{2}$ Fruit and Vegetable Processing Plant "ROMEX" Janina Moryl, Wielopole 89, 33-210 Olesno, Poland \\ ${ }^{3}$ Department of Carbohydrate Technology, Faculty of Food Technology, University of Agriculture in Krakow, Krakow, Poland \\ Correspondence should be addressed to Anna Korus; rrkorusa@cyf-kr.edu.pl
}

Received 15 November 2017; Revised 13 February 2018; Accepted 5 March 2018; Published 23 April 2018

Academic Editor: Amy Simonne

Copyright (C) 2018 Anna Banaś et al. This is an open access article distributed under the Creative Commons Attribution License, which permits unrestricted use, distribution, and reproduction in any medium, provided the original work is properly cited.

The aim of this research was to evaluate texture, color, and sensory parameters of low-sugar gooseberry jams with added black chokeberry, elderberry, Japanese quince, flax seeds, wheat germ, and inulin. The jams were stored at two temperatures of $10^{\circ} \mathrm{C}$ and $20^{\circ} \mathrm{C}$. The highest gel strength $\left(F_{e}\right)$ was recorded in the jams with wheat germ $(2.75 \mathrm{~N})$, flax seeds $(2.74 \mathrm{~N})$, and inulin $(1.95 \mathrm{~N})$. The brightest color $\left(L^{*}\right)$ was noted in the gooseberry jams enriched with flax seeds and wheat germ, while the darkest color was noted in those with added black chokeberry and elderberry fruit. In the sensory evaluation, the gooseberry jam without plant ingredients, along with the products enriched with black chokeberry, elderberry, and inulin, scored high at almost 5 on a 5-point scale. The remaining jams had scores of 4.4-4.8 points. Cool storage of jams had a better effect on color and texture, while sensory features were affected to a lesser degree.

\section{Introduction}

The implication of increasing knowledge about the impact of individual food components on human health is a modification of nutritional recommendations. According to the latest nutritional recommendations, vegetables and fruits should form the basis of our diet [1-4]. These raw materials provide many valuable constituents such as vitamins, minerals, and polyphenols, reducing the risk of cardiovascular disease and cancer. As was reported by numerous studies, berries in particular are a very good source of health-promoting compounds [5].

Gooseberry is one of the berry species that contains numerous biologically active compounds [6]. It is grown mainly in Europe and its largest producers are Germany, where its production amounted to 83 thousand tonnes in 2016; Russia, with 66 thousand tonnes; and Poland, with 12 thousand tonnes [7]. Gooseberry belongs to the category of seasonal fruits; therefore, in order to prolong its availability it is mainly processed into jams, jellies, and juices [8].
Jams are made by combining sugar, pulp, and/or puree from one or more types of fruit, water, and gelling agents [9]. Due to the increasing number of health problems occurring in society, caused by obesity, metabolic syndrome, and diabetes, the demand for the products with reduced calorie content has increased on the market [10]. Therefore, particularly low-sugar jams, in which some of the sucrose has been replaced by sweeteners (e.g., sorbitol, xylitol, or steviol glycosides), are valued by consumers [11, 12]. Steviol glycosides are natural sweeteners, which, apart from their sweetening properties, exhibit antioxidant, antibacterial, and antiviral effects $[13,14]$.

The functional food market is developing very dynamically. In 2015, this market generated a global revenue of 129 billion US dollars and is projected to reach 250 billion US dollars by 2024 [15]. Such a large demand for this type of food is reflected in numerous studies conducted, among others, on the enrichment of jams with health-promoting components $[12,13,16-18]$. The valuable bioactive compounds are polyphenols, including anthocyanins, occurring, i.a., in chokeberry and black elderberry. Anthocyanins from these 
raw materials, as natural colorants, give the products an attractive appearance. In addition, raw materials abundant in natural fiber, including flax seeds and wheat germ, are used in functional foods. Fiber reduces the level of blood glucose and cholesterol [19] as well as protecting against colon cancer [20]. It also has valuable technological properties, as it prevents syneresis, and improves the texture and sensory properties of food [21]. Inulin, the prebiotic with textureforming properties, is a special type of dietary fiber [10, 22].

Color is one of the most important quality parameters of jams; it is closely related to the perception and reception of the product $[16,18,23-25]$. This parameter is evaluated first during purchase and is fundamental for the consumer acceptance or rejection of the product. Changes in the color of jams are caused by many factors, mainly $\mathrm{pH}$, metal ions, temperature, light, oxygen, enzymes, and sugars and their degradation products [26], as well as storage conditions $[18,27,28]$. Therefore, color assessment should be performed and may be accomplished visually, by a trained panel and/or instrumentally. The instrumental color measurement is repeatable and enables the preassessment of the extent of the colorants' transformation in the product. This measurement may be particularly helpful for storage tests. On the other hand, the visual assessment of the color allows for the assessment of the whole product, the structure of which is often nonhomogenous [29].

The texture significantly affects the final assessment of the product [30]. Improper texture can make the product unacceptable to the consumer, even if it tastes very good. Texture feeling is perceived by the consumer as an assessment of product freshness, for example, bread crispiness, vegetable hardness, or jam spreadability. In turn, the lack of these features suggests poor quality and may make the product unacceptable [31, 32]. Numerous reports confirm that jam consistency depends on the amount and type of sweeteners, gelling agents, and fruit flesh $[13,33]$. One of the methods used to assess jam structure is its evaluation by a trained sensory panel. However, the instrumental measurement of texture profile, including hardness or adhesiveness, allows for an objective evaluation of this parameter and a comparison of the changes occurring in texture [34].

A number of studies have been conducted concerning texture assessment and the sensory characteristics of fruit jams [16, 18, 33, 35, 36]. However, gooseberry fruit, despite its high nutritional value and attractive sensory characteristics, is very rarely used as a raw material for making jams. The aim of this study was the enrichment of gooseberry jam with prohealth ingredients as well as its evaluation immediately after production and throughout a one-year storage at two temperatures $\left(10^{\circ} \mathrm{C}\right.$ and $\left.20^{\circ} \mathrm{C}\right)$. The novel approach of the presented research was the evaluation of the effect of adding elderberry, Japanese quince, flax seeds, wheat germ, and inulin to gooseberry jam on the texture, color, and sensory attributes of the jam.

\section{Materials and Methods}

2.1. Materials. The research material was low-sugar jam obtained from gooseberry (Ribes uva-crispa, cv. Invicta), without added plant ingredients and jams enriched with black chokeberry [Aronia melanocarpa (Michx.) Elliott], elderberry (Sambucus nigra L.) Japanese quince [Chaenomeles japonica (Thunb.) Lindl. ex Spach], flax seeds (Linum usitatissimum L.), wheat germ (Triticum aestivum L.), and inulin.

The jams were produced from frozen fruits. Fully mature (with an even color, intensive taste, and aroma) and fresh fruits (immediately after harvest) were sorted and washed, rejecting inedible parts. Gooseberry fruits were frozen whole. The freezing of gooseberries included the following operations: sorting to eliminate damaged and poorly colored fruit, washing and on sieves to remove water before freezing. The fruits of chokeberry, elderberry, and Japanese quince were homogenized prior to freezing. The fruits were then frozen on trays in a freezing chamber at $-40^{\circ} \mathrm{C}$. After freezing, products were packed into polypropylene bags, approved for food production use, and freeze-stored in a freezing chamber at $-30^{\circ} \mathrm{C}$ for a month, until needed for jam production.

Flax seeds (Oleofarm, Wrocław, Poland), ground and defatted, were added in the form of ground seeds obtained due to the process of deffating. Wheat germ, derived from wheat grains, were purchased directly from the producer (Sante, Warszawa, Poland). An inulin Orafti GR preparation (BENEO-Orafti, Mannheim, Germany) with DP $\geq 10$ was also added to the jams.

The following ingredients were also used in the production of jams: sucrose, steviol glycoside (Bio Nature24, Warszawa, Poland) as a partial sucrose replacement, citrusapple pectin (NECJ-A2, Naturex, Avignon, France), and citric acid (Chem Point, Kraków, Poland). Steviol glycoside was added at a ratio of $200 \mathrm{mg} / 1000 \mathrm{~g}$ of the product, which allowed for partial sucrose replacement and a reduction in the jams' caloric value.

2.2. Production of Jam. Fruit comprised $50 \%$ of the mass of the final product. It was assumed that the extract content in jams will be $30 \%$ (measured by a refractometer) and that the total acidity will be at the level of $1 \mathrm{~g}$ of citric acid/100 $\mathrm{g}$ of the product. The total acidity, calculated per citric acid, was determined by a titration method. Jams were prepared in the following variants:

(i) GO: gooseberry jam without plant ingredients, with only sucrose as a sweetener (control sample)

(ii) GS: gooseberry jam without plant ingredients, with sucrose and steviol glycoside as sweeteners

(iii) GCh: gooseberry jam containing $15 \%$ (w/w) of black chokeberry

(iv) GE: gooseberry jam containing $15 \%(w / w)$ of elderberry

(v) GJ: gooseberry jam containing $8 \%(w / w)$ of Japanese quince

(vi) GF: gooseberry jam containing 3\% (w/w) of ground flax seeds

(vii) GWG: gooseberry jam containing 3\% (w/w) of wheat germ 
TABLE 1: Recipes of gooseberry jams, g/kg of finished product.

\begin{tabular}{|c|c|c|c|c|c|c|c|c|c|c|c|c|}
\hline \multirow{2}{*}{ Type of jams ${ }^{b}$} & \multicolumn{12}{|c|}{ Ingredients $^{\mathrm{a}}$} \\
\hline & G & $\mathrm{Ch}$ & $\mathrm{E}$ & $\mathrm{J}$ & $\mathrm{F}$ & WG & I & Sucrose & Steviol glycoside & Pectin & Citric acid & Water \\
\hline G0 & 500 & & & & & & & 303 & 0.0 & 11.2 & 2.0 & 183 \\
\hline GS & 500 & & & & & & & 255 & 0.2 & 11.2 & 2.0 & 231 \\
\hline GCh & 350 & 150 & & & & & & 246 & 0.2 & 11.2 & 2.6 & 240 \\
\hline GE & 350 & & 150 & & & & & 250 & 0.2 & 11.2 & 2.6 & 235 \\
\hline GJ & 420 & & & 80 & & & & 255 & 0.2 & 11.2 & 0.0 & 233 \\
\hline GF & 500 & & & & 30 & & & 246 & 0.2 & 16.0 & 2.0 & 201 \\
\hline GWG & 500 & & & & & 30 & & 246 & 0.2 & 16.0 & 2.0 & 201 \\
\hline GI & 500 & & & & & & 100 & 173 & 0.2 & 11.2 & 2.0 & 213 \\
\hline
\end{tabular}

${ }^{\mathrm{a}} \mathrm{G}$ : gooseberry, Ch: black chokeberry, E: elderberry, J: Japanese quince, F: flax seeds, WG: wheat germ, and I: inulin. ${ }^{\mathrm{b}}$ Type of jams: G0: gooseberry jam without plant ingredients, with only sucrose as a sweetener, GS: gooseberry jam without plant ingredients, with sucrose and steviol glycoside as sweeteners, GCh: gooseberry jam containing $15 \%$ (w/w) of black chokeberry, GE: gooseberry jam containing $15 \%(w / w)$ of elderberry, GJ: gooseberry jam containing $8 \%$ (w/w) of Japanese quince, GF: gooseberry jam containing 3\% (w/w) of ground flax seeds, GWG: gooseberry jam containing 3\% (w/w) of wheat germ, and GI: gooseberry jam containing $10 \%(\mathrm{w} / \mathrm{w})$ of inulin.

(viii) GI: gooseberry jam containing $10 \%(w / w)$ of inulin.

All the jams with plant ingredients were sweetened with sucrose and steviol glycoside. Two technological repetitions were made from each variant of the jam. After weighing the ingredients according to the formulations given in Table 1, the fruits together with sweeteners and water were cooked in an open pan until there was a refractometric extract of about $35 \%$ and sugar saturation of the fruit $\left(20 \mathrm{~min}, 103^{\circ} \mathrm{C}\right)$. Then, a gelling agent solution (4\%) was added and all the ingredients were thoroughly mixed. After that, the mixture was cooked for about 3 min and finally citric acid was added. The whole mixture was then stirred again. The jams obtained were poured into unit packages (glass jars; $0.2 \mathrm{~L}$ ), pasteurized at $82-85^{\circ} \mathrm{C}$ for $15 \mathrm{~min}$, in a water bath pasteurizer. After pasteurization, the jams were cooled to $20 \pm 2^{\circ} \mathrm{C}$. The applied parameters of jam pasteurization were established based on own research [37] and information from fruit and vegetable processing plants, which are producing jams and apply for many years such parameters in preserving such products.

2.3. Storage of the Jams. Jams were stored at cool temperature $\left(10^{\circ} \mathrm{C}\right)$ and at room temperature $\left(20^{\circ} \mathrm{C}\right)$ until the analyses. They were analyzed immediately after manufacture and after 6 and 12 months of storage.

2.4. Texture Analysis. Analysis of jam texture was performed, following Genovese et al. [38], by means of a TA-XT2plus texturometer (Stable Micro Systems, Surrey, England). The following conditions were applied: compression rate of $2 \mathrm{~mm} / \mathrm{sec}$, the $\mathrm{P} / 20$ probe $(20 \mathrm{~mm}$ in diameter) moving to a penetration depth of $20 \mathrm{~mm}$, and a trigger force of $1 \mathrm{~g}$. Before the analyses, the samples were conditioned at room temperature. Every sample was analyzed in five replications, using five different unit packages of jam. Jam texture was established using the following texture indicators: $F_{e}(\mathrm{~N})$ - gel strength (force at a point in the initial stage of penetration, where little deformation has occurred), FR (N)-rupture force (the rupture point of the gel), $E(\mathrm{~N} \mathrm{~s})$ - energy of penetration (area under the first pick), and $A(\mathrm{~N} \mathrm{~s})$-adhesiveness (area under the negative region of the curve). The $F_{e}, \mathrm{FR}$, and $E$ parameters refer to the hardness of the gel, while the $A$ parameter indicates its tendency to adhere to different surfaces. The results were calculated using Texture Exponent software (Stable Micro Systems, Surrey, England).

2.5. Instrumental Color Analysis. Measurement of upper surface color was carried out with the use of Konica MINOLTA CM-3500d equipment (Konica Minolta Inc., Tokyo, Japan) with reference to illuminant D65 and a visual angle of $10^{\circ}$. The results were expressed using the CIE $\left(L^{*} a^{*} b^{*}\right)$ system [39]. The established color parameters were as follows: $L^{*}$ (lightness) -0 is black, and 100 is white; $a^{*}$ redness $(+)$ greenness $(-) ; b^{*}$ yellowness $(+)$ blueness $(-)$; and $C^{*}-$ the color saturation value (chroma) as well as $h^{\circ}$-the hue angle. There were five replicates for each sample. Color differences $\left(\Delta E^{*}\right)$ between samples were calculated according to the CIE formula [39]:

$$
\Delta E^{*}=\left[\left(\Delta L^{*}\right)^{2}+\left(\Delta a^{*}\right)^{2}+\left(\Delta b^{*}\right)^{2}\right]^{1 / 2} .
$$

2.6. Sensory Evaluation. Sensory evaluation was carried out by a panel of 15 subjects, fulfilling the requirements for sensory sensitivity according to the requirements of ISO 3972 [40] under ISO 6658 [41] recommended conditions. The samples were evaluated using a standard five-point scale from 1 (the lowest grade) to 5 (the highest grade) (for a detailed description, see Supplementary material available here). The individual quality features were evaluated using significance factors: external appearance of the product surface (syneresis) - 2; structure (disposition of fruit parts in the content of jam)-3; color-4; consistency-3; aroma (type and desirability) - 4; and taste (type and desirability) -4 . These factors were determined based on the opinion of panellists, whose experience in sensory evaluation and profound acquaintance with this type of product were acknowledged. The samples stored at $10^{\circ} \mathrm{C}$ were taken out 4 hours prior to evaluation.

2.7. Statistical Analysis. The results referring to texture and color parameters were analyzed statistically using a 
two-factor analysis of variance (factor I-type of jam, factor II-storage), while those for sensory evaluation were analyzed by means of a one-factor analysis on the basis of the Snedecor $F$ test and Student's $t$-test. The least significant difference (LSD) was calculated at a probability level of $p<$ 0.05. The Statistica 12.0 program was applied (StatSoft, Tulsa, USA).

\section{Results and Discussion}

3.1. Texture Analysis. Pectin is the main factor determining jam consistency and its content and type have an effect on gel hardness $[42,43]$. Thus, in order to assess jam hardness, the values of gel strength $\left(F_{e}\right)$, rupture force (FR), and energy of penetration $(E)$, referring to gel hardness, were measured, along with adhesiveness $(A)$.

Immediately after manufacture, the values of gel strength in the investigated jams were within the range of 1.04-2.87 N (Table 2). The hardest jams were those with added flax seed $(2.87 \mathrm{~N})$, wheat germ $(2.59 \mathrm{~N})$, and inulin $(2.34 \mathrm{~N})$. In the remaining products, the $F_{e}$ value did not exceed $1.70 \mathrm{~N}$. In turn, the rupture force (FR) ranged from 1.41 to $4.12 \mathrm{~N}$ and was the highest in the jams enriched with wheat germ and flax seed (Table 2). These findings are consistent with those of Raj et al. [44], who enriched papaya jam with whey, which incorporates proteins in the jam, as was the case when adding flax seeds and wheat germ. These compounds, as exhibiting both gelling properties and the capability of water retention, increase hardness.

Throughout storage there were different tendencies in the level of $F_{e}$ value, depending on the plant ingredients used and the storage conditions. In comparison with the sample taken immediately after production, after a 6-month storage period the gel strength decreased on average by $7-12 \%$. This could be due to the decomposition of pectin compounds by the acids present in the product and consistency relaxation, which was also reported by Morris et al. [45] and Korus et al. [37]. After 12 months of storage, the level of Fe value increased by $2-12 \%$, compared to the nonstored samples, which could have resulted from the degradation of cellulose to the soluble fiber. Jams stored at lower temperature were generally harder, both after 6 and after 12 months of storage. A similar trend was observed for the FR parameter when measuring the rupture force of the jam. The FR value, which decreased by $9-16 \%$ in the first stage of the storage period, then increased by $1-11 \%$, compared to the samples analyzed directly after manufacture. After a year's storage, the highest values of $F_{e}$ and FR parameters were shown by the jams coded GWG and GF (Table 2). According to Raj et al. [44], the hardness of the papaya jam with added whey increased after 60 days of storage at room temperature. In contrast, Korus et al. [37] reported that the gel strength of bilberry jams with herbal additives decreased after 8 months of storage. On the other hand, Kopjar et al. [43] revealed that the hardness of lowsugar strawberry jam decreased after two weeks of storage and then increased. After 6 weeks, the hardness of these jams was $19 \%$ higher than the initial value. As the authors claim, such behaviour results from various mechanisms of gel formation.
Energy of penetration $(E)$ of the nonstored gooseberry jams was in the range of $13.27-33.58 \mathrm{~N}$ s, depending on the applied plant ingredients (Table 2). In comparison with the jam without plant ingredients (control), the increase in the $E$ value was the highest in gooseberry jams with added wheat germ, flax seed, and inulin, by $96 \%, 84 \%$, and $40 \%$, respectively. During storage, as with $F_{e}$ and FR values, the level of the $E$ parameter decreased, on average by $8-11 \%$, after 6 months, and after 6 successive months it increased by $11-16 \%$. The storage temperature significantly affected $(p<0.05)$ the energy of jam penetration; the value was lower at higher storage temperature. Storage conditions, particularly temperature, have a substantial effect on pectin depolymerization, as was also reported by Morris et al. [45].

The adhesiveness of nonstored gooseberry jams ranged between -0.71 and $-1.86 \mathrm{~N}$ s (Table 2 ). Compared to the control (G0), adding black chokeberry, elderberry, and Japanese quince to gooseberry jam led to a decrease in the examined parameter; the largest (35\%) change was in the GE jam. A reduction in the $A$ parameter was also observed in the GS jam, in which a part of the sucrose was replaced with steviol glycoside. In contrast, the addition of flax seeds, wheat germ, and inulin caused an increase in the adhesiveness of the investigated samples by $7-69 \%$ compared to the control sample. This is due to the fact that flax seeds contain protein and fiber, while mucus and proteins also occur in wheat germs. These compounds have good hydrophilic properties, since they can bind several to a dozen or so times more water compared to their mass. Inulin, as a constituent of dietary fiber, also has the ability to bind water and create gels. At the beginning of the storage period, the value of the A parameter determined in gooseberry jams decreased by $8-11 \%$ compared to nonstored samples and then increased by $10-18 \%$, depending on the storage temperature. Korus et al. [37] observed a decrease in the adhesiveness of bilberry jams after 8 months of storage, while Raj et al. [44] observed an increase in this parameter in the whey-enriched papaya jams stored at room temperature for 60 days.

It is difficult to determine accurately the mechanisms and the potential reasons for the differences in these parameters in the evaluated products, since jams are a multicomponent system. As it was with the strength/hardness of the gel, an observed decrease in adhesiveness could be related to the degradation of pectin, which, under the influence of temperature and $\mathrm{pH}$, undergo depolymerization [45]. In turn, an increase in hardness after 12 months of storage could be a result of the polymerization of low-molecular-weight compounds or the interaction between jam components $[46,47]$. For example, polyphenols can interact with many food components, for example, with protein, strengthening its structure [48]. Kopjar et al. [43] reported a decrease in the firmness and consistency of strawberry jam stored at $4^{\circ} \mathrm{C}$ for two weeks and an increase in the values of these parameters after 4 and 6 weeks of storage, which the authors explain by citing the different mechanisms of gel formation through the reactions of different types of pectin. An increase in adhesiveness after 12 months of storage could in turn be the result of changes in carbohydrates. 
TABLE 2: Changes in texture parameters of gooseberry jam during storage in $10^{\circ} \mathrm{C}$ and $20^{\circ} \mathrm{C}$.

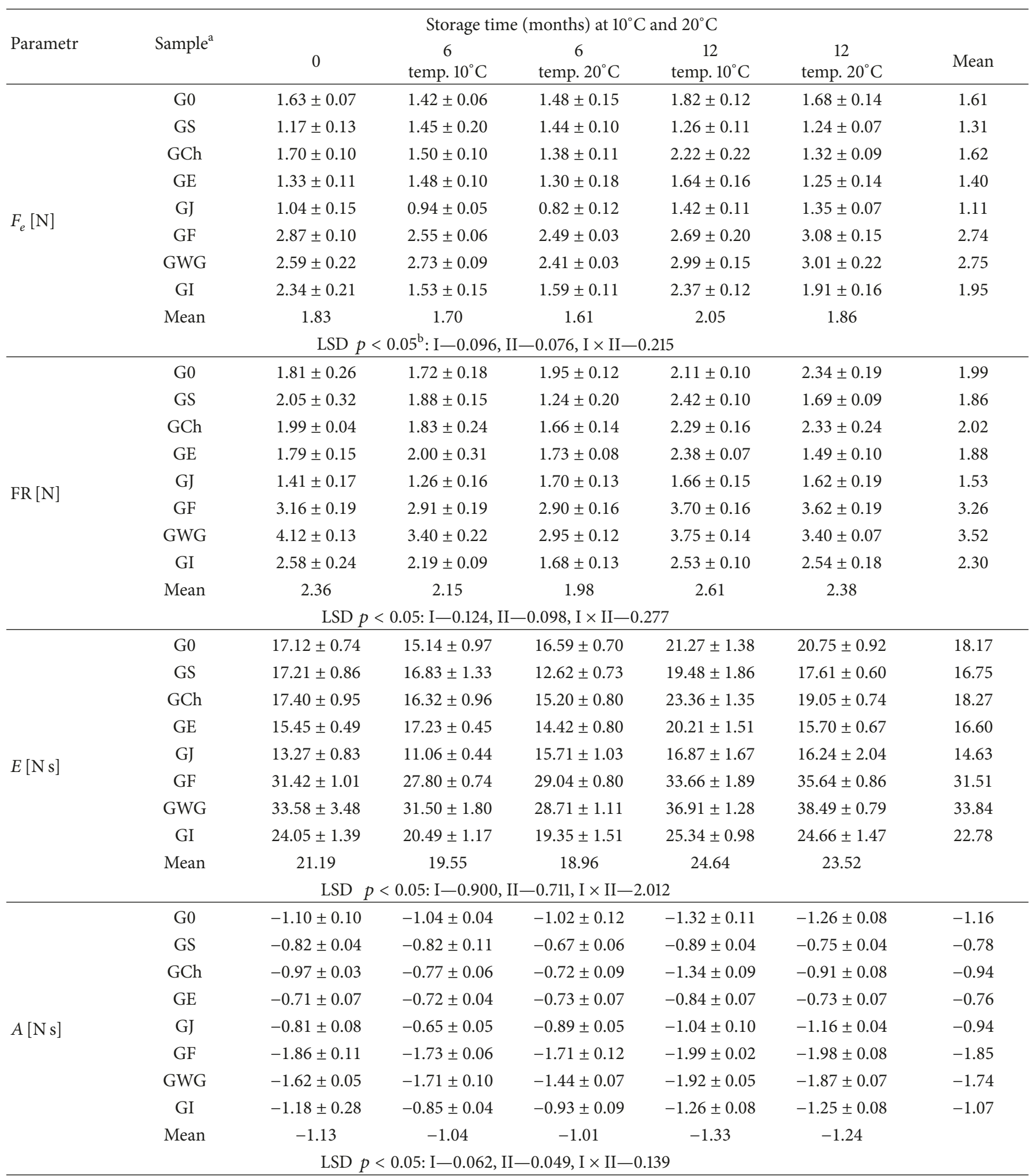

Values are presented as mean value $\pm \mathrm{SD}(n=5) .{ }^{\mathrm{a}}$ Sample: G0: gooseberry jam without plant ingredients, with only sucrose as a sweetener, GS: gooseberry jam without plant ingredients, with sucrose and steviol glycoside as sweeteners, GCh: gooseberry jam containing 15\% (w/w) of black chokeberry, GE: gooseberry jam containing $15 \%(w / w)$ of elderberry, GJ: gooseberry jam containing $8 \%(w / w)$ of Japanese quince, GF: gooseberry jam containing 3\% (w/w) of ground flax seeds, GWG: gooseberry jam containing $3 \%(w / w)$ of wheat germ, and GI: gooseberry jam containing $10 \%(w / w)$ of inulin ${ }^{b} L S D p<0.05$ for Sample (I), Storage (II), and Interaction (I × II). 
TABLE 3: Changes in color parameters $\left(L^{*}, a^{*}\right.$, and $\left.b^{*}\right)$ of gooseberry jams during storage in $10^{\circ} \mathrm{C}$ and $20^{\circ} \mathrm{C}$.

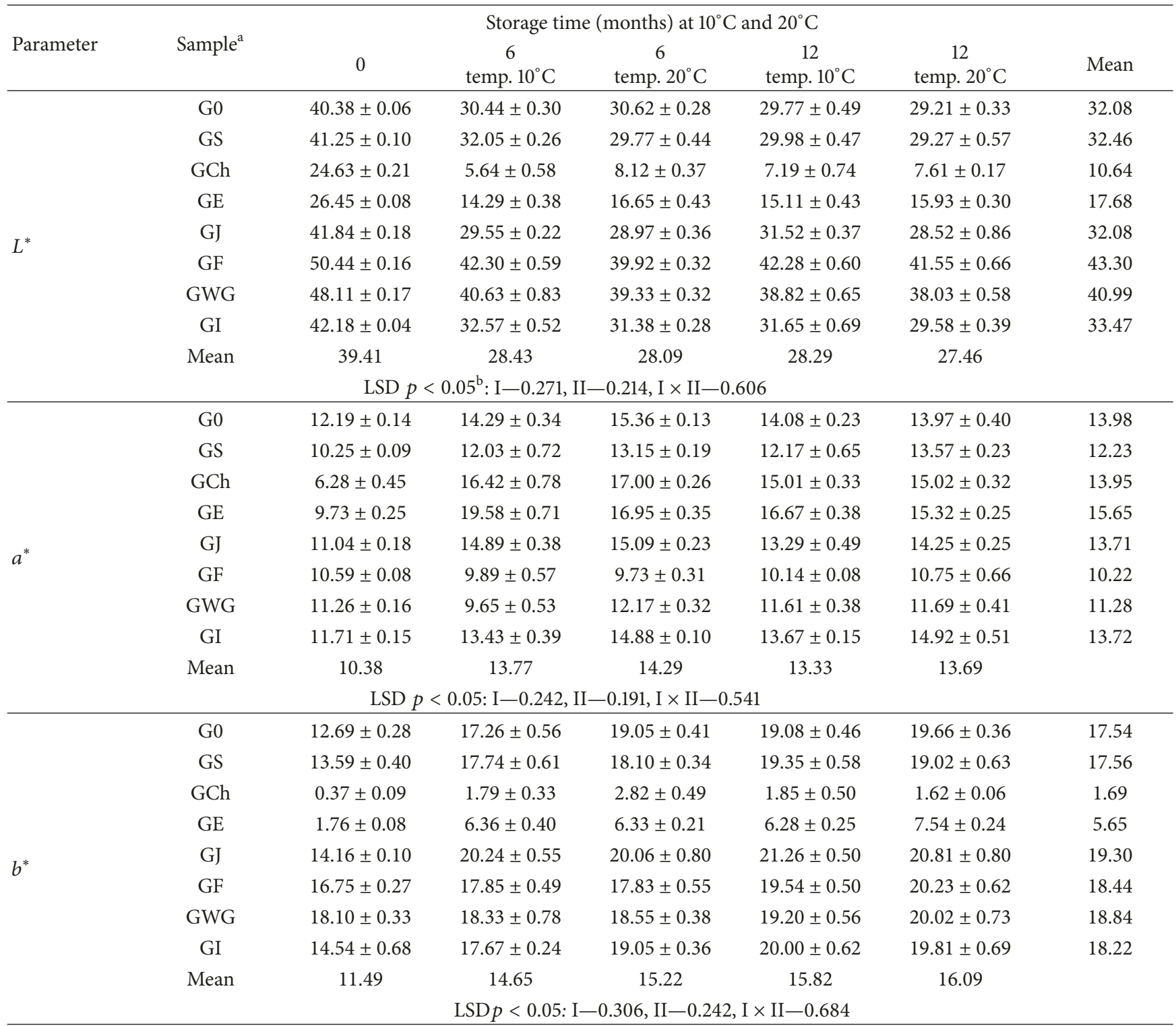

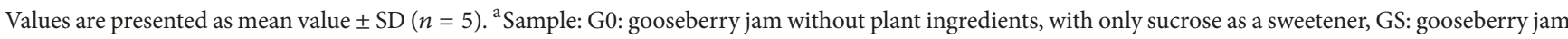
without plant ingredients, with sucrose and steviol glycoside as sweeteners, GCh: gooseberry jam containing 15\% (w/w) of black chokeberry, GE: gooseberry jam containing $15 \%(\mathrm{w} / \mathrm{w})$ of elderberry, GJ: gooseberry jam containing $8 \%(\mathrm{w} / \mathrm{w})$ of Japanese quince, GF: gooseberry jam containing $3 \%$ (w/w) of ground flax seeds, GWG: gooseberry jam containing $3 \%(w / w)$ of wheat germ, and GI: gooseberry jam containing $10 \%$ (w/w) of inulin ${ }^{b} \mathrm{LSD} p<0.05$ for Sample (I), Storage (II), and Interaction (I × II).

Patel et al. [49], during the 9-month storage of the bananapineapple blended jam, observed an increase in the contents of both total sugars and reducing sugars, which they attributed to the breakdown of insoluble polysaccharides into simple sugars. The results of texture analysis obtained during short-term (6 weeks) experiments [43] and longterm (12 months) studies presented here suggest that the texture of jam is not a stable system; in such a system, changes occur dynamically, even during a one-year storage period.

3.2. Instrumental Color Analysis. Color is one of the fundamental criteria for the visual assessment of jams. In gooseberry jams, directly after manufacture, the $L^{*}$ parameter determining color brightness fluctuated between 24.63 and 50.44 (Table 3). The addition of black chokeberry and elderberry to jams caused the largest decrease in the $L^{*}$ value, by $39 \%$ and $34 \%$, respectively, when compared to the control sample without plant ingredients. These jams were characterized by the darkest color resulting from the anthocyanin-rich fruit additives. $L^{*}$ values determined in gooseberry jams with added elderberry and black chokeberry were similar to those reported by Rababah et al. [50] in cherry jam (27.51) and by Wojdyło et al. [51] in strawberry jam enriched with chokeberry fruit (27.92). In turn, the jam enriched with flax seeds and wheat germ, the color of 
which was lighter than the control sample by $25 \%$ and $19 \%$, respectively, proved to be the lightest of the examined jams. The brightening of these samples could have been due to the addition of light-colored plant additives such as wheat germ and flax seeds $(3 \% \mathrm{w} / \mathrm{w})$. Similar lightening of jams was reported by Grigelmo-Miguel et al. [52] after adding peach fiber to strawberry jam. In the remaining gooseberry jams, the value of the $L^{*}$ parameter was close to that of the control sample.

During jam storage, a gradual decrease in the $L^{*}$ parameter was observed resulting in the products' darkening. After a 6-month storage period at cool temperature, the decrease in lightness was greatest in the GCh and GE jams. Jams stored at a higher temperature were generally darker in color, which deepened with storage time. Similar trends were observed by Wicklund et al. [25]. Changes in the color of anthocyaninrich jams are not only caused by Maillard's reaction. They mainly result from transformations of anthocyanins, which, in addition to browning, also increase the yellow coloration, which was confirmed by Ścibisz et al. [53]. On the other hand, Maillard's reaction and the products of nonenzymatic browning occurring during storage have the greatest effect on the color of jams with low anthocyanin content [54].

In the samples examined immediately after production, the value of the $a^{*}$ parameter was in the range of 6.28-12.19 (Table 3). Enrichment of gooseberry jam with plant ingredients reduced the value of the $a^{*}$ parameter, compared to the control, which indicates a reduction in the proportion of the red color. The greatest decrease was observed after adding black chokeberry (48\%) and elderberry (20\%). The value of the $a^{*}$ parameter fluctuated over the period of the jams' storage. After 6 and 12 months of storage, the increase in the proportion of red color was generally slight. AbdelHady et al. [26] and Wojdyło et al. [51] also recorded changes in the $a^{*}$ parameter during the storage of strawberry jams, depending on the additives applied.

Table 3 shows the values of the $b^{*}$ parameter, which were within the range of yellow coloration (0.37-18.10). The lowest values were found in jams with added black chokeberry (0.37) and elderberry (1.76). On the contrary, the highest yellow coloration was observed in the jams containing flax seeds (16.75) and wheat germ (18.10), which is a natural consequence of the color of these ingredients. Throughout the storage period, the proportion of yellow color increased depending on temperature and storage time, on average, by $38 \%\left(10^{\circ} \mathrm{C}\right)$ and $40 \%\left(20^{\circ} \mathrm{C}\right)$, respectively, when compared to the control sample. Rababah et al. [50], who examined cherry jams, also found a larger increase in the $b^{*}$ parameter in the products stored at higher temperatures.

The lowest value of the $C^{*}$ parameter was determined in fruit jams enriched with black chokeberry (5.89) and elderberry (9.92), which were darkest among the evaluated jams (Table 4). The remaining jams were characterized by saturated color (17.08-21.38), which is perceived by the human eye as a vibrant color. During storage, the $C^{*}$ value was generally higher at cool temperature than at room temperature.
In gooseberry jams, the value of the $h^{\circ}$ parameter was within the yellow coloration range (46.09-58.15). The exceptions were the black chokeberry and elderberry jams, for which the $h^{\circ}$ value was within the red-purple coloration range. This, in turn, means that the $h^{\circ}$ value was the lowest in the jams coded GCh (3.16) and GE (10.19) (Table 4). In all the jams, this value increased with storage time and was higher in those stored at room temperature compared to those stored at $10^{\circ} \mathrm{C}$. This indicates the degradation of red pigments and the shift towards yellow coloration. Pinelli et al. [55] also noted an increase in the $h^{\circ}$ parameter of strawberry jams after 120 days of storage.

The color difference $\left(\Delta E^{*}\right)$ between two samples determines color perception by a human observer. Color difference can be interpreted as follows: $0<\Delta E^{*}<1$-difference in color is visually nonrecognizable by a standard observer; $1<\Delta E^{*}<2$-the difference is visually recognizable only by an experienced observer; $2<\Delta E^{*}<3.5$-the difference can be visually recognized by an inexperienced observer; $3.5<\Delta E^{*}<5$-every observer can easily see the difference; and $\Delta E^{*}>5$-an observer recognizes two different colors $[56,57]$. In the examined gooseberry jams, the smallest differences in color were recorded between the jam without plant ingredients (G0) and jams coded GS, GJ, and GI; however, these were visually recognizable by an inexperienced observer (Table 4). In contrast, in the remaining cases, the differences were significant and thus recognized by every observer. In nonstored jams, the highest $\Delta E^{*}$ value referred to the jam with added chokeberry (20.85). Throughout storage, color differences $\left(\Delta E^{*}\right)$ were visually recognizable in all samples.

3.3. Sensory Evaluation. Sensory features are one of the determinants of a consumer's choice of food. Sensory evaluation of gooseberry jam was conducted using the 5-point scale. Immediately after manufacture, the highest values (4.9-5.0 pts) were scored by the jams without plant ingredients (control), those partially sweetened with steviol glycoside and those enriched with black chokeberry, elderberry, Japanese quince, and inulin (Table 5). Slightly lower scores (4.7) were achieved by the jams with added wheat germ and flax seeds due to the floury aftertaste of wheat germ as well as color deterioration, which was estimated to be $22-26 \%$ compared to the control sample.

The sensory quality of the examined jams was decreasing during storage, except in the case of the jam with added black chokeberry, which scored the highest value (5.0 pts) during the whole storage period, that is, after 6 and 12 months. Similar trends were noted by Abdel-Hady et al. [26], who reported a decrease in the sensory properties of strawberry jam throughout storage. However, adding purple carrot puree had a substantial effect on the color stabilization in the jams during their manufacture and storage. The coolstored samples of gooseberry jam were characterized by better sensory quality. Numerous scientific reports confirm the substantial effect of temperature on the quality of final products during storage $[53,58]$. In all the analyzed samples, there was no syneresis on the surface and fruits were evenly distributed in the whole mass which was reflected in the high 
TABLE 4: Changes in chroma ${ }^{*}\left(C^{*}\right)$, hue angle* $\left(h^{\circ}\right)$, and color change $\left(\Delta E^{*}\right)$ of gooseberry jams during storage in $10^{\circ} \mathrm{C}$ and $20^{\circ} \mathrm{C}$.

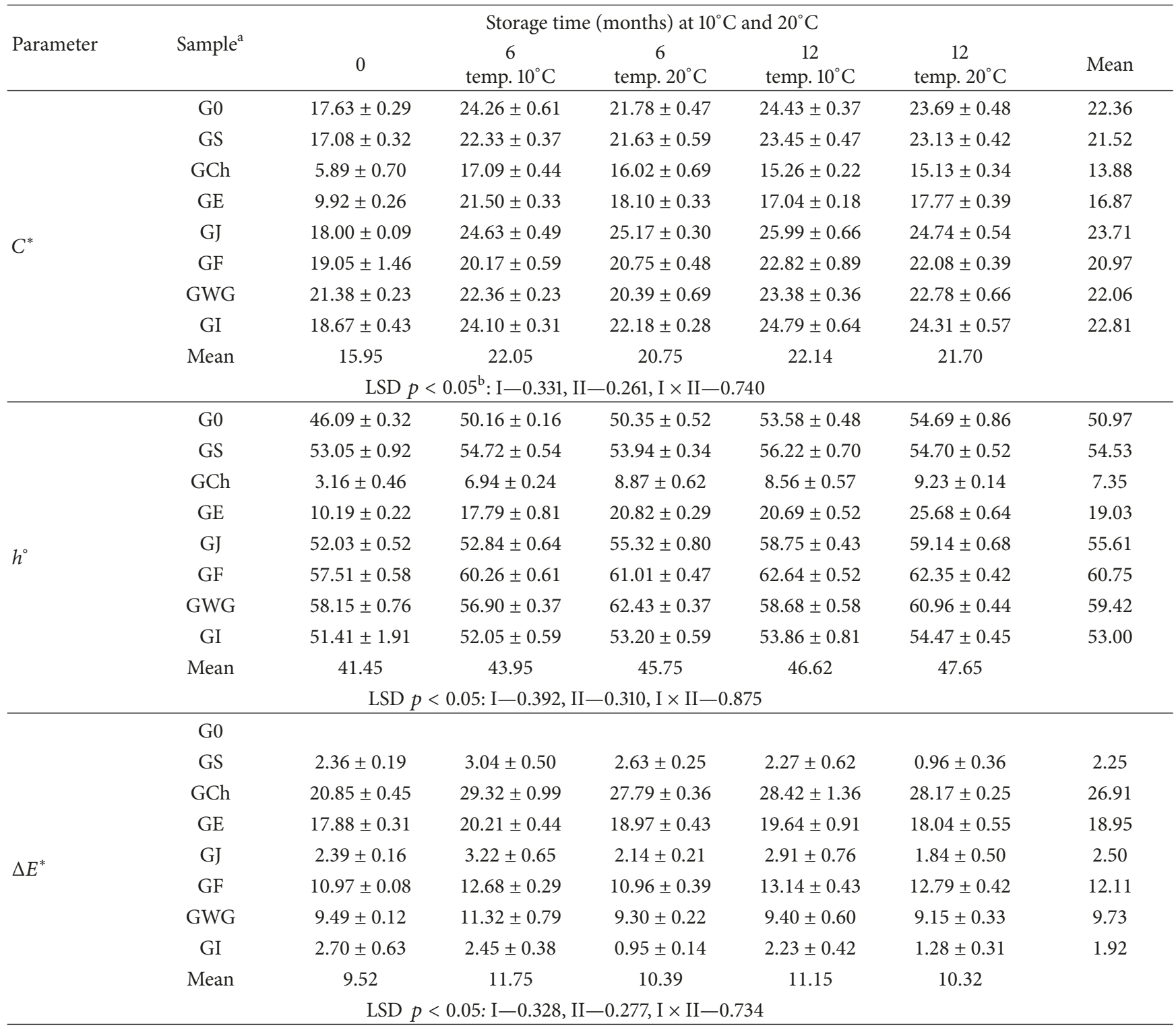

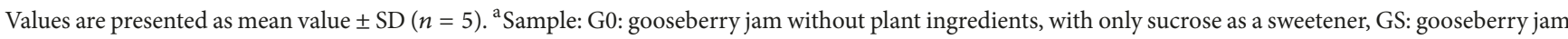
without plant ingredients, with sucrose and steviol glycoside as sweeteners, GCh: gooseberry jam containing $15 \%$ (w/w) of black chokeberry, GE: gooseberry jam containing $15 \%(w / w)$ of elderberry, GJ: gooseberry jam containing $8 \%(w / w)$ of Japanese quince, GF: gooseberry jam containing $3 \%$ (w/w) of ground flax seeds, GWG: gooseberry jam containing $3 \%(w / w)$ of wheat germ, and GI: gooseberry jam containing $10 \%(w / w)$ of inulin. ${ }^{b} \mathrm{LSD} p<0.05$ for Sample (I), Storage (II), and Interaction $(\mathrm{I} \times \mathrm{II})$.

scores for these indicators. The jam without plant ingredients (control sample) and the jams enriched with plant-derived raw materials exhibited intense aroma, very good taste, and intense color and achieved final scores ranging from 4.6 to 5.0 points. The taste and aroma of the jams containing flax seeds and wheat germ were scored slightly lower, within 4.4-4.5 and 4.0-4.6 points, respectively. These jams, however, had the worst color, with a brownish coloration, which influenced the low rating for this sensory indicator (3.5-3.7 pts). GrigelmoMiguel et al. [52] observed a similar change in the color of strawberry jams with added peach fiber during their storage. As the amount of fiber added to strawberry jam increased, their color was more and more dark.

\section{Conclusions}

The investigated gooseberry jams, which were enriched with plant ingredients showing prohealth properties, can be a valuable supplement to a diet as they meet the current demand for healthy food. Moreover, in such jams, the partial replacement of sucrose with steviol glycoside enables energy value reduction; such products, in turn, enjoy great popularity among consumers. Assessments of texture parameters, color, and sensory attributes by means of instrumental methods as well as by a trained sensory panel make it possible to determine a product's acceptability for consumption. The texture of gooseberry jam weakened in the first half of 


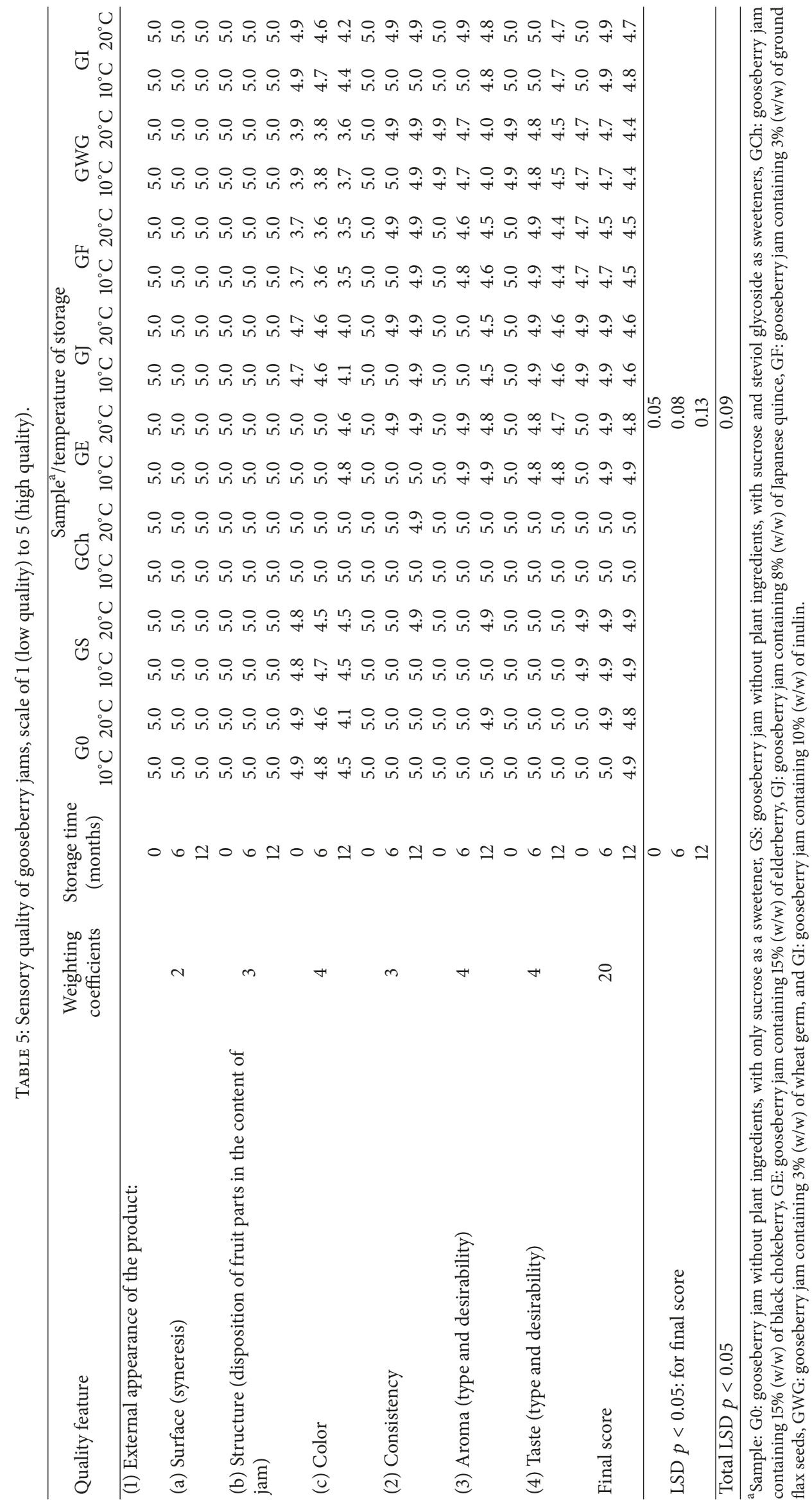


storage, after which it increased in the samples examined after a 12-month storage period. The analyzed jams achieved very high scores in the sensory evaluation immediately after production (4.7-5.0 pts) and slightly lower ones after 12 months of storage (4.4-5.0 pts). Therefore, it can be said that the enriching plant ingredients (black chokeberry, elderberry, Japanese quince, flax seeds, wheat germ, and inulin) can be a valuable supplement to this type of product. At the same time, it should be emphasized that jams should be cool-stored and, in the case of jams with added flax seeds and wheat germ, it would be advisable to shorten their storage time to 6 months.

\section{Conflicts of Interest}

The authors declare that there are no conflicts of interest regarding the publication of this paper.

\section{Acknowledgments}

This research was financed by the Ministry of Science and Higher Education of the Republic of Poland.

\section{Supplementary Materials}

The Quality.doc file contains a detailed description of the quality factors used in the sensory evaluation of the examined jams. (Supplementary Materials)

\section{References}

[1] Safefood, The Food Pyramid and The Eatwell Guide, 2016, http://www.safefood.eu/Healthy-Eating/What-is-a-balanceddiet/The-Food-Pyramid.aspx, [Accessed on 2018.1.27].

[2] Food Politics, Nestle M. Belgium's new food pyramid, 2017, http://www.foodpolitics.com/2017/10/belgiums-new-food-pyramid, [Accessed on 2018.1.27].

[3] National Health and Medical Research Council, Australian Guide to Healthy Eating, 2018, http://www.eatforhealth.gov.au/ guidelines/australian-guide-healthy-eating, [Accessed on 2018 .1.27].

[4] USDA Center for Nutrition Policy and Promotion, "ChooseMyPlate.gov," 2018, http://www.choosemyplate.gov, [Accessed on 2018.1.27].

[5] I. Muraki, F. Imamura, J. E. Manson et al., "Fruit consumption and risk of type 2 diabetes: Results from three prospective longitudinal cohort studies," British Medical Journal, vol. 347, Article ID f5001, 2013.

[6] M. Anastasiadi, P. M. Mwangi, J. J. Ordaz-Ortiz et al., "Tissue biochemical diversity of 20 gooseberry cultivars and the effect of ethylene supplementation on postharvest life," Postharvest Biology and Technology, vol. 117, pp. 141-151, 2016.

[7] FAOSTAT, Food and agriculture data. Available from: http:// www.fao.org/faostat/en/\#data/QC, 2016 [Accessed on 2018 .1.27].

[8] D. L. Barney and K. E. Hummer, Currants, gooseberries, and jostaberries: A guide for growers, marketers, and researchers in north America, CRC Press, Hawthorn, 2005.

[9] Council Directive 2004/84/EC, "Council Directive 2004/84/EC of 10 June 2004 amending Directive 2001/113/EC relating to fruit jams, jellies and marmalades and sweetened chestnut purée intended for human consumption," 2004.

[10] M. Krystyjan, D. Gumul, R. Ziobro, and M. Sikora, "The Effect of Inulin as a Fat Replacement on Dough and Biscuit Properties," Journal of Food Quality, vol. 38, no. 5, pp. 305-315, 2015.

[11] V. R. De Souza, P. A. P. Pereira, A. C. M. Pinheiro, H. M. A. Bolini, S. V. Borges, and F. Queiroz, "Analysis of various sweeteners in low-sugar mixed fruit jam: Equivalent sweetness, timeintensity analysis and acceptance test," International Journal of Food Science \& Technology, vol. 48, no. 7, pp. 1541-1548, 2013.

[12] R. M. Abolila, H. Barakat, H. A. El-Tanahy, and H. A. El-Mansy, "Chemical, Nutritional and Organoleptical Characteristics of Orange-Based Formulated Low-Calorie Jams," Journal of Food and Nutrition Sciences, vol. 06, no. 13, pp. 1229-1244, 2015.

[13] S. Basu, U. S. Shivhare, and T. V. Singh, "Effect of substitution of stevioside and sucralose on rheological, spectral, color and microstructural characteristics of mango jam," Journal of Food Engineering, vol. 114, no. 4, pp. 465-476, 2013.

[14] R. Lemus-Mondaca, A. Vega-Gálvez, L. Zura-Bravo, and A.H. Kong, "Stevia rebaudiana Bertoni, source of a high-potency natural sweetener: A comprehensive review on the biochemical, nutritional and functional aspects," Food Chemistry, vol. 132, no. 3, pp. 1121-1132, 2012.

[15] Market Research Report, "Functional Foods Market Analysis By Product (Carotenoids, Dietary Fibers, Fatty Acids, Minerals, Prebiotics \& Probiotics, Vitamins), By Application, By EndUse (Sports Nutrition, Weight Management, Immunity, Digestive Health) And Segment Forecasts," https://www.grandviewresearch.com/industry-analysis/functional-food-market, [Accessed on 2018.1.27], 2016.

[16] M. Igual, C. Contreras, and N. Martínez-Navarrete, "Colour and rheological properties of non-conventional grapefruit jams: Instrumental and sensory measurement," LWT- Food Science and Technology, vol. 56, no. 1, pp. 200-206, 2014.

[17] M. Belović, A. Torbica, I. Pajić-Lijaković, and J. Mastilović, "Development of low calorie jams with increased content of natural dietary fibre made from tomato pomace," Food Chemistry, vol. 237, pp. 1226-1233, 2017.

[18] M. Abid, H. Yaich, H. Hidouri, H. Attia, and M. A. Ayadi, "Effect of substituted gelling agents from pomegranate peel on colour, textural and sensory properties of pomegranate jam," Food Chemistry, vol. 239, pp. 1047-1054, 2018.

[19] C. Agostoni, J. L. Bresson, S. Fairweather Tait et al., "Scientific opinion on dietary reference values for carbohydrates and dietary fibre," EFSA Journal, vol. 8, no. 3, pp. 462-539, 2010.

[20] R. Rodríguez, A. Jiménez, J. Fernández-Bolaños, R. Guillén, and A. Heredia, "Dietary fibre from vegetable products as source of functional ingredients," Trends in Food Science \& Technology, vol. 17, no. 1, pp. 3-15, 2006.

[21] N. O'Shea, E. K. Arendt, and E. Gallagher, "Dietary fibre and phytochemical characteristics of fruit and vegetable byproducts and their recent applications as novel ingredients in food products," Innovative Food Science and Emerging Technologies, vol. 16, pp. 1-10, 2012.

[22] N. Kaur and A. K. Gupta, "Applications of inulin and oligofructose in health and nutrition," Journal of Biosciences, vol. 27, no. 7, pp. 703-714, 2002.

[23] D. Bursać, N. Vahčić, B. Levaj, V. Dragović-Uzelac, and A. Biško, "The influence of cultivar on sensory profiles of fresh and processed strawberry fruits grown in Croatia," Flavour and Fragrance Journal, vol. 22, no. 6, pp. 512-520, 2007. 
[24] I. Klimczak and M. Małecka, "Evaluation of sensory profile and p-vinylguaiacol (pvg) content in orange juices during storage at different temperature," Journal of Food Quality, vol. 34, no. 1, pp. 30-39, 2011.

[25] T. Wicklund, H. J. Rosenfeld, B. K. Martinsen et al., "Antioxidant capacity and colour of strawberry jam as influenced by cultivar and storage conditions," LWT - Food Science and Technology, vol. 38, no. 4, pp. 387-391, 2005.

[26] M. M. Abdel-Hady, Y. A. Gamila, and M. A. Afaf, "Color stability of strawberry jam fortified by purple carrot puree," Egyptian Journal of Agricultural Research, vol. 92, no. 1, pp. 323336, 2014.

[27] N. Touati, F. J. Barba, H. Louaileche, A. Frigola, and M. J. Esteve, "Effect of Storage Time and Temperature on the Quality of Fruit Nectars: Determination of Nutritional Loss Indicators," Journal of Food Quality, vol. 39, no. 3, pp. 209-217, 2016.

[28] R. E. Wrolstad, R. W. Durst, and J. Lee, "Tracking color and pigment changes in anthocyanin products," Trends in Food Science \& Technology, vol. 16, no. 9, pp. 423-428, 2005.

[29] V. Eyarkai Nambi, K. Thangavel, S. Shahir, and V. Thirupathi, "Comparison of Various RGB Image Features for Nondestructive Prediction of Ripening Quality of "Alphonso" Mangoes for Easy Adoptability in Machine Vision Applications: A Multivariate Approach," Journal of Food Quality, vol. 39, no. 6, pp. 816$825,2016$.

[30] M. Valente, F. Ribeyre, G. Self, L. Berthiot, and S. Assemat, "Instrumental and sensory characterization of mango fruit texture," Journal of Food Quality, vol. 34, no. 6, pp. 413-424, 2011.

[31] E. Aprea, F. Biasioli, F. Gasperi, T. D. Märk, and S. van Ruth, "In vivo monitoring of strawberry flavour release from model custards: Effect of texture and oral processing," Flavour and Fragrance Journal, vol. 21, no. 1, pp. 53-58, 2006.

[32] M. M. Løkke, H. F. Seefeldt, and M. Edelenbos, "Freshness and sensory quality of packaged wild rocket," Postharvest Biology and Technology, vol. 73, pp. 99-106, 2012.

[33] S. Basu and U. S. Shivhare, "Rheological, textural, microstructural and sensory properties of mango jam," Journal of Food Engineering, vol. 100, no. 2, pp. 357-365, 2010.

[34] M. A. Chauvin, C. F. Ross, M. Pitts, E. Kupferman, and B. Swanson, "Relationship between instrumental and sensory determination of apple and pear texture," Journal of Food Quality, vol. 33, no. 2, pp. 181-198, 2010.

[35] S. Basu, U. S. Shivhare, T. V. Singh, and V. S. Beniwal, "Rheological, textural and spectral characteristics of sorbitol substituted mango jam," Journal of Food Engineering, vol. 105, no. 3, pp. 503$512,2011$.

[36] J.-T. Fu and M. A. Rao, "Rheology and structure development during gelation of low-methoxyl pectin gels: The effect of sucrose," Food Hydrocolloids, vol. 15, no. 1, pp. 93-100, 2001.

[37] A. Korus, G. Jaworska, E. Bernaś, and L. Juszczak, "Characteristics of physico-chemical properties of bilberry (Vaccinium myrtillus L.) jams with added herbs," Journal of Food Science and Technology, vol. 52, no. 5, pp. 2815-2823, 2015.

[38] D. B. Genovese, A. Ye, and H. Singh, "High methoxyl pectin/ apple particles composite gels: effect of particle size and particle concentration on mechanical properties and gel structure," Journal of Texture Studies, vol. 41, no. 2, pp. 171-189, 2010.

[39] CIE, Colorimetry, Commission Internationale de l'Eclairage, Vienna, Austria, 2004.

[40] ISO, "Sensory analysis - Methodology - Method of investigating sensitivity of taste," International Organization for Standardization, 1998.
[41] ISO, "Sensory analysis - Methodology - General guidance," International Organization for Standardization, 1998.

[42] P. Dervisi, J. Lamb, and I. Zabetakis, "High pressure processing in jam manufacture: effects on textural and colour properties," Food Chemistry, vol. 73, no. 1, pp. 85-91, 2001.

[43] M. Kopjar, V. Piližota, N. N. Tiban et al., "Strawberry jams: Influence of different pectins on colour and textural properties," Czech Journal of Food Sciences, vol. 27, no. 1, pp. 20-28, 2009.

[44] A. Raj, P. Albert, K. Radha, M. Vijayalakshmi, S. Pavulraj, and P. Anuradha, "Study on the utilization of paneer whey as functional ingredient for papaya jam," Italian Journal of Food Science, vol. 29, no. 1, pp. 171-184, 2017.

[45] G. A. Morris, J. Castile, A. Smith, G. G. Adams, and S. E. Harding, "The effect of different storage temperatures on the physical properties of pectin solutions and gels," Polymer Degradation and Stability, vol. 95, no. 12, pp. 2670-2673, 2010.

[46] M. Buchweitz, M. Speth, D. R. Kammerer, and R. Carle, "Impact of pectin type on the storage stability of black currant (Ribes nigrum L.) anthocyanins in pectic model solutions," Food Chemistry, vol. 139, no. 1-4, pp. 1168-1178, 2013.

[47] M.-A. Poiana, M.-F. Munteanu, D.-M. Bordean, R. Gligor, and E. Alexa, "Assessing the effects of different pectins addition on color quality and antioxidant properties of blackberry jam," Chemistry Central Journal, vol. 7, no. 1, pp. 121-133, 2013.

[48] Y. Song and S.-H. Yoo, "Quality improvement of a ricesubstituted fried noodle by utilizing the protein-polyphenol interaction between a pea protein isolate and green tea (Camellia sinensis) extract," Food Chemistry, vol. 235, pp. 181-187, 2017.

[49] N. V. Patel, A. G. Naik, and A. K. Senapati, "Quality evaluation and storage study of banana - pineapple blended jam," International Journal of Food Quality and Safety, vol. 1, pp. 45-51, 2015.

[50] T. M. Rababah, M. Al-U’Datt, M. Al-Mahasneh et al., "Effect of Jam processing and storage on phytochemicals and physiochemical properties of cherry at different temperatures," Journal of Food Processing and Preservation, vol. 38, no. 1, pp. 247-254, 2014.

[51] A. Wojdyło, J. Oszmiański, and I. Bober, "The effect of addition of chokeberry, flowering quince fruits and rhubarb juice to strawberry jams on their polyphenol content, antioxidant activity and colour," European Food Research and Technology, vol. 227, no. 4, pp. 1043-1051, 2008.

[52] N. Grigelmo-Miguel, S. Gorinstein, and O. Martín-Belloso, "Characterisation of peach dietary fibre concentrate as a food ingredient," Food Chemistry, vol. 65, no. 2, pp. 175-181, 1999.

[53] I. Ścibisz, A. Gasik, M. Mitek, and A. Cendrowski, "Effect of storage conditions on colour of jams made from colourful fruits," Żywność. Nauka. Technologia. Jakość, vol. 18, no. 1, pp. 99-111, 2011.

[54] M. Rada-Mendoza, M. L. Sanz, A. Olano, and M. Villamiel, "Formation of hydroxymethylfurfural and furosine during the storage of jams and fruit-based infant foods," Food Chemistry, vol. 85, no. 4, pp. 605-609, 2004.

[55] L. L. O. Pinelli, C. L. Moretti, M. Chiarello, and L. Melo, "Influence of strawberry jam color and phenolic compounds on acceptance during storage," Revista Ceres, vol. 2, no. 3, pp. 233240, 2015.

[56] W. S. Mokrzycki and M. Tatol, "Colour difference $\Delta \mathrm{E}$ - a survey," Machine Graphics and Vision, vol. 20, no. 4, pp. 383-411, 2011.

[57] A. M. Rogowska, Synaesthesia and individual differences, Cambridge University Press, UK, 2015. 
[58] C. Cardelli and T. P. Labuza, "Application of weibull hazard analysis to the determination of the shelf life of roasted and ground coffee," LWT - Food Science and Technology, vol. 34, no. 5, pp. 273-278, 2001. 


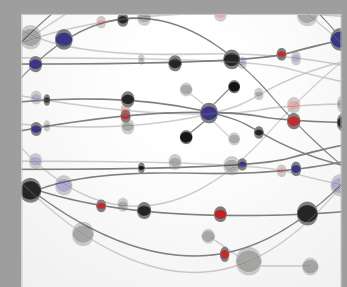

The Scientific World Journal
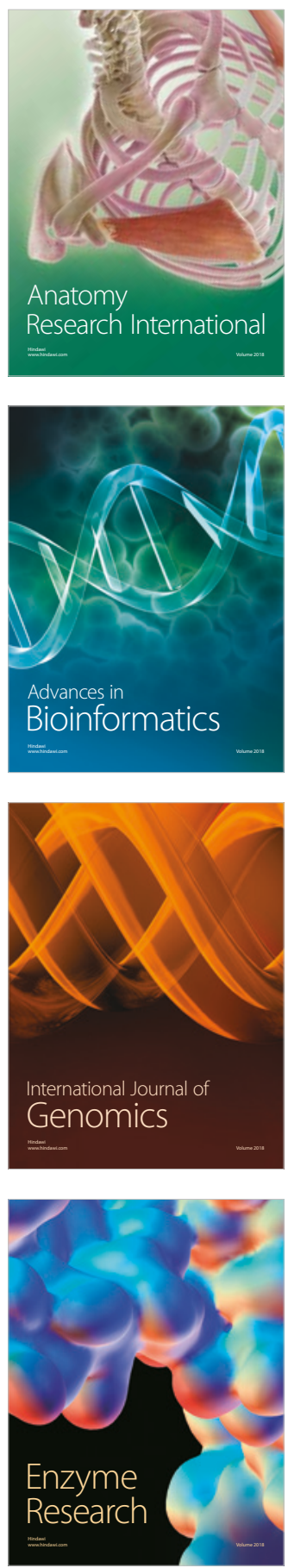
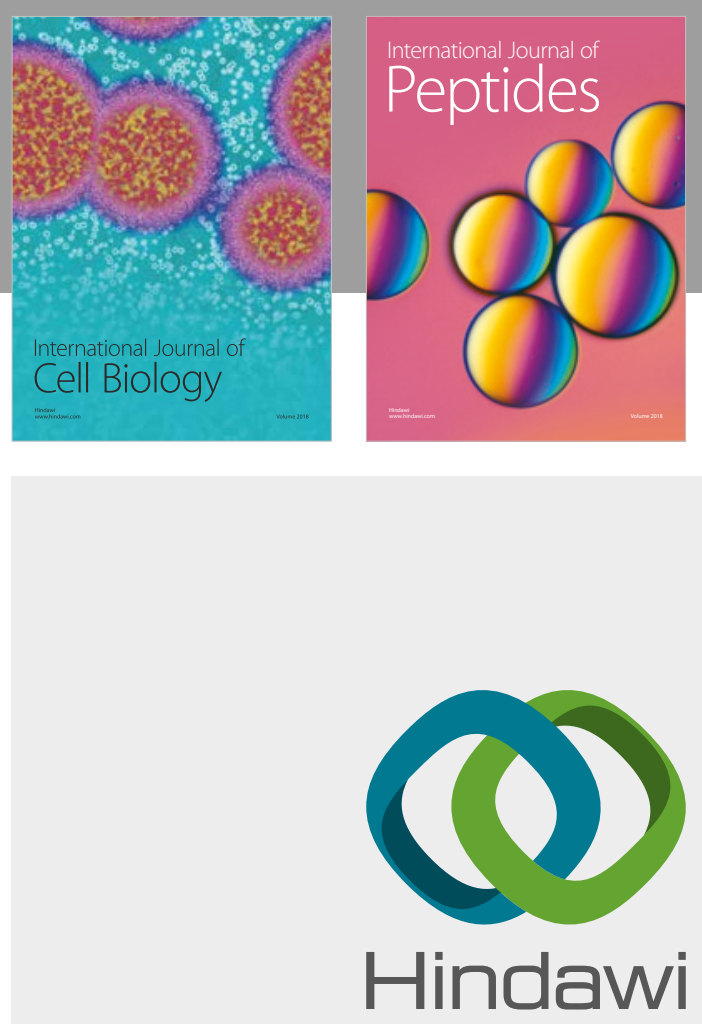

Submit your manuscripts at

www.hindawi.com
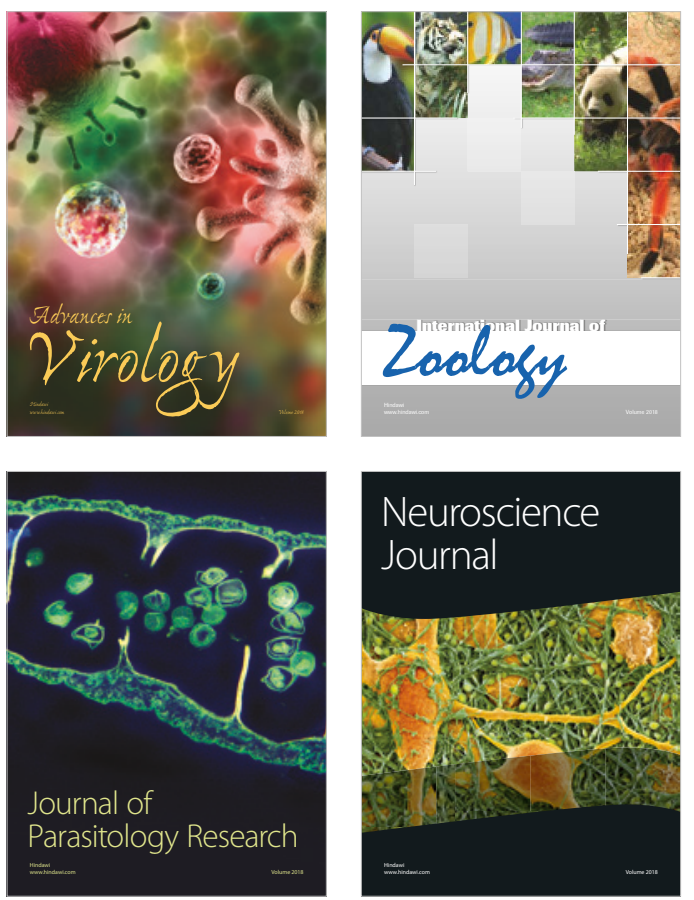
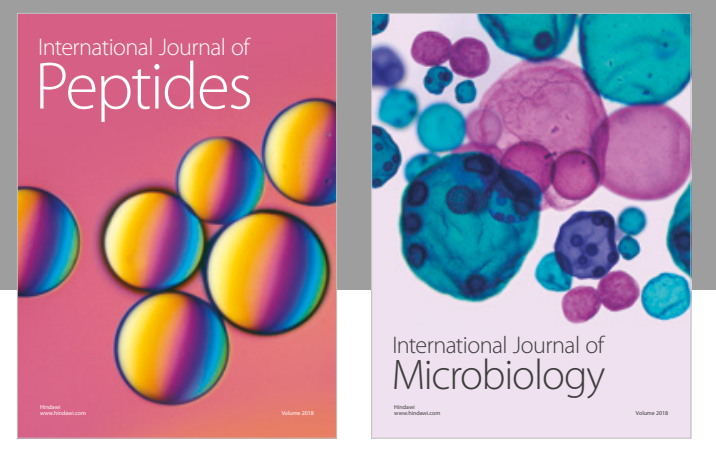

nternational Journal of Microbiology
Journal of
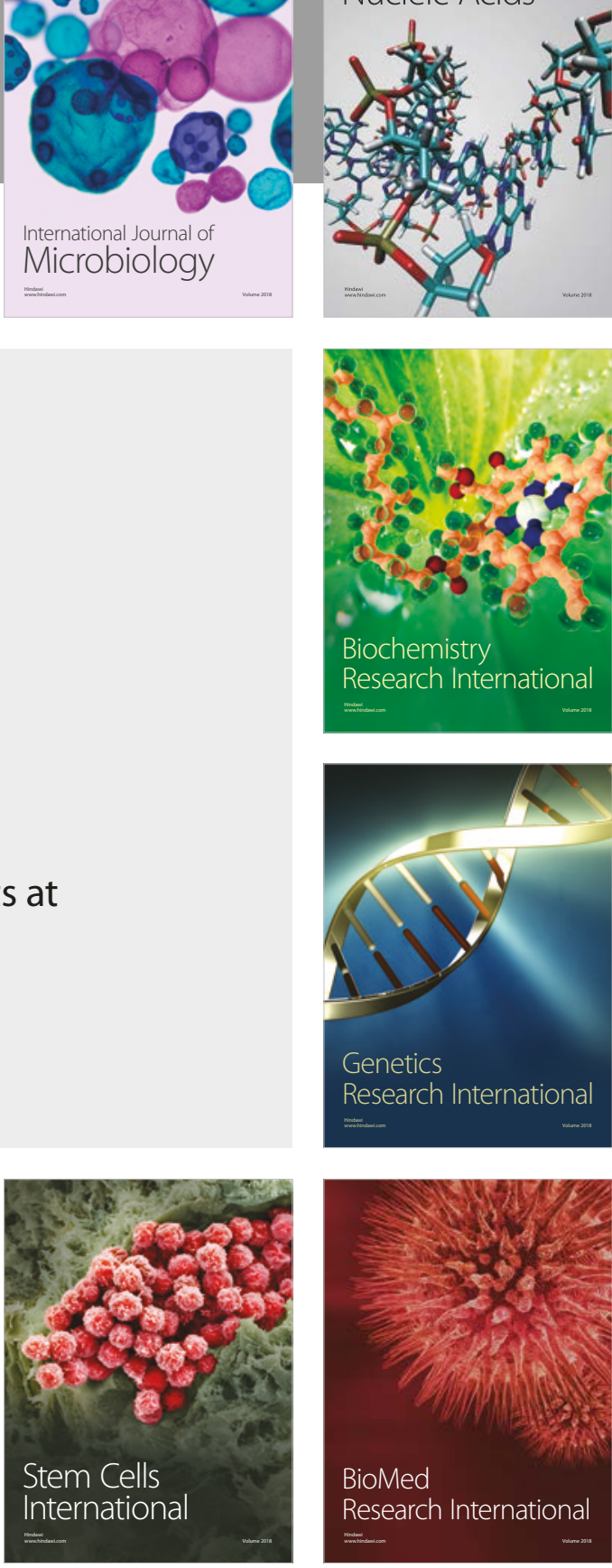
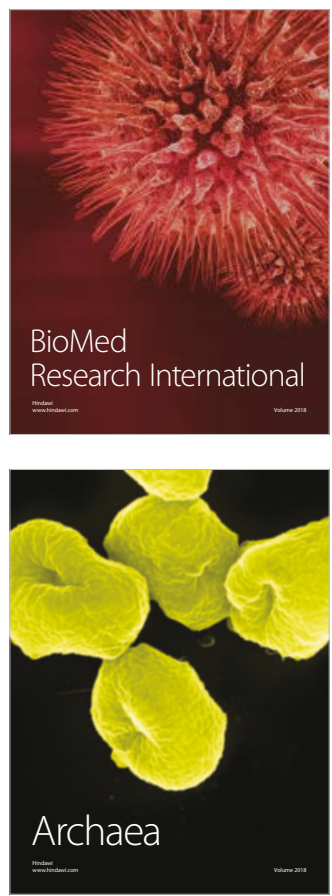